\title{
ANALYSIS OF INTRADAY TRADING OF INDEX OPTION IN KOREAN OPTION MARKET
}

\author{
Young-Hoon Ko \\ Department of Computer Engineering, HyupSung University, South Korea
}

\begin{abstract}
The option market in South Korea began on 7 July 1997. After then, the amount of option market has increased steeply. In these days, average daily payments is beyond 1 trillion won.

It is impossible to predict the market. But using the statistics, investors can get a profit steadly.

The open interest contracts of index future has increased over 4000 after start time of a day and decrease down to about 0 when closing time.

As for this characteristics of index future, $\mathrm{Ko}^{[1]}$ suggested the volatility strategy and brought the result of simulation with the profit of $1.07 \%$ per a day. This profit comes to real if an investor finds a brokerage firm with low commissions.

This paper suggests another strategy. The price of options consists of time value and intrinsic value. And the fall of index future is faster than rising. Therefore velocity of moving index cause the price of options. The simulation results give a fascinating fact that put option tends to increase in the morning and call option tends to increase in the afternoon.

With this velocity strategy, investors get the profit $1.4 \%$ per a day except commissions of $0.15 \%$ per one trade.
\end{abstract}

\section{KEYWORDS}

Automatic Trading System, Volatility Strategy, Velocity Strategy, Open interest Contract

\section{INTRODUCTION}

The option market in South Korea began on 7 July 1997. An underlying asset of option market is KOSPI200 index which consist of 200 superior symbols in KOSPI. Stock index future began on 3 May 1996.

According to the statistics of Korea exchange(KRX), the average daily payments of index options was just 50 billion won in January 2000, it had increased and reached up 500 billion won in March 2002. And then it reached 1 trillion won in June 2007. It was up to 2.5 trillion won in August 2011. In these days it is about 1 1.5 trillion won

David C. Wyld et al. (Eds) : CST, ITCS, JSE, SIP, ARIA, DMS - 2014

pp. 65-74, 2014. (C) CS \& IT-CSCP 2014

DOI : $10.5121 /$ csit.2014.4107 
Monthly average daily trading payments is shown in the following graph.

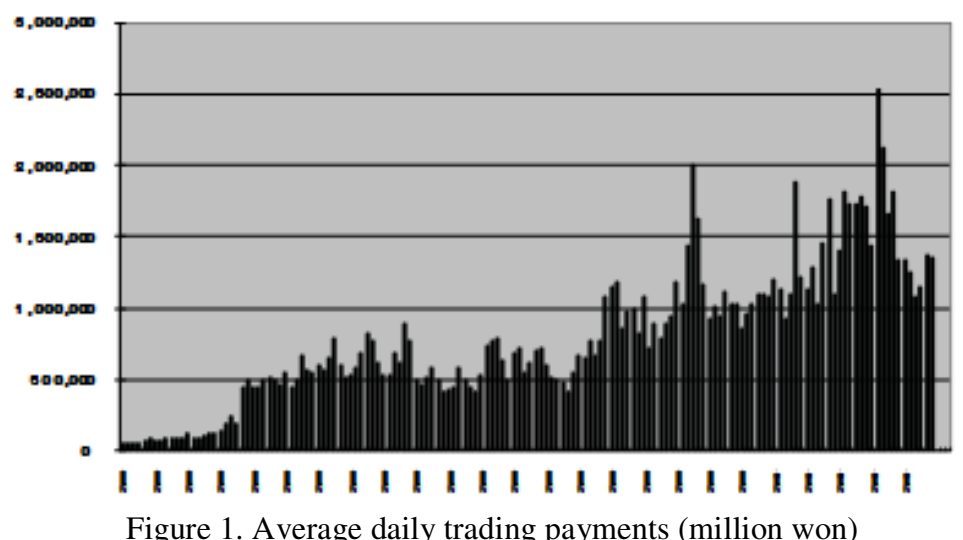

Call-put ratio is shown in the following graph. The volume of call option is more than put option's in early 2000 decade. But after 2003, there is a trend that the volume of put option has increased more than call option's. Especially, in the months with a big fall of index, the volume of put option is $50 \%$ more than call option's.

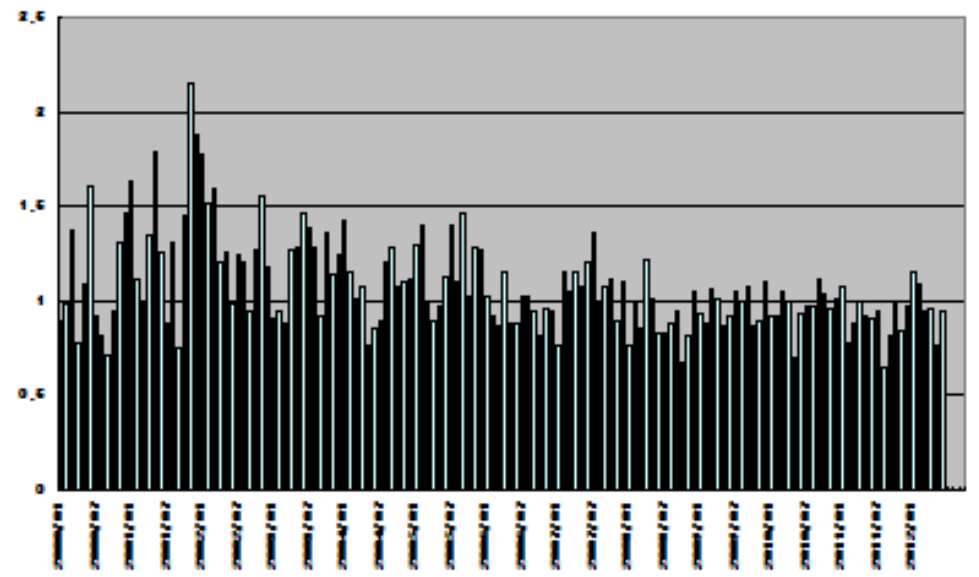

Figure 2. Call-put ratio by average daily trading contracts

Option is in the derivative market, It is not to trade stock such as real asset but it makes contracts mutually by abstract index of stocks. This type of contracts must be liquidated. The amount of contracts which is not yet liquidated is called open interest contracts.

It is impossible to predict the market. If the investors can predict the future market, the market cannot be established because everyone wants to trade one side.

However, in stock market there is sure one thing. It is that every contract has its own expiration date.

\section{OPEN INTEREST CONTRACTS}

Since 2008, nearly two year average of open interest contracts of index futures showed as a followed graph. 


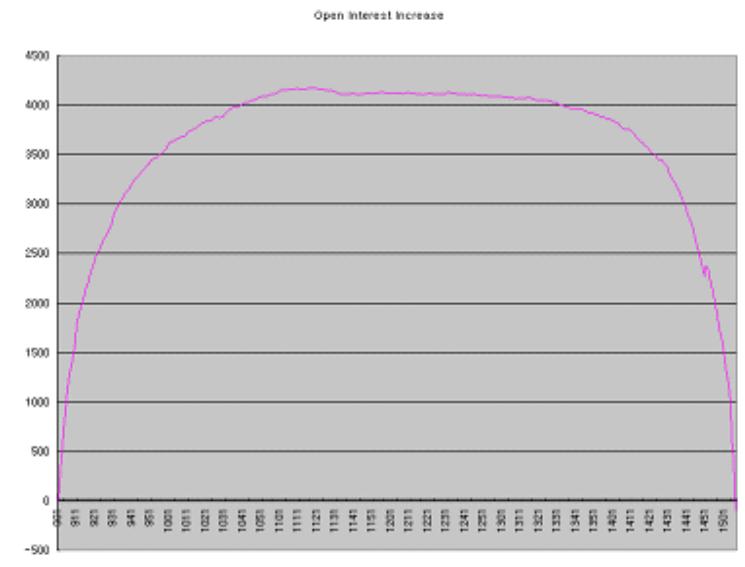

Figure 3. OID(average open interest contracts difference from the start time) (2-year)

As for minute candles, the difference between the close value of a candle and the close value of first candle at 9:00 is considered as the y-axis value. OID is used as abbreviation for open interest contracts difference from the start time of a day.

The OID at 9:00 is 0 and it is increasing over 4000 by around 10:40 and it reduces down to about 0 until closing time at 15:00. This curve appears due to the nature of the intraday trading of stock index futures.

Stock index futures and options trading is held from 9:00 to $15: 15$. From 15:05 to $15: 15$ is progressed simultaneously and investors can not know the asking and bid price, purchase orders and sell orders determine the closing price at 15:15.

Stocks that is an underlying asset of futures are trading from 9:00 to 15:00.

Therefore, the trade after 15:00 until 9:00 the following day will not be able. If some event happens during this period, it will make a big gap at start of the next trade time. the event of disaster can result in huge losses to position investors who sold options and held it overnight.

For this reasen, a lot of unpredictability, most investors are trying to avoid the risk of overnight. Theoretically, option sell, especially in the case of possible loss of the margins, often wearing heavy losses occur.

Thus, investors in order to avoid overnight risk of the day tend to focus on daily marketing, which open interest contracts of index futures increase and decrease is illustrated look.

Next graph shows OID with the longer average duration of five years. The shape is almost same but a little difference occurs as the table below. Second graph include late two years, so it shows trend of recent characteristics. 


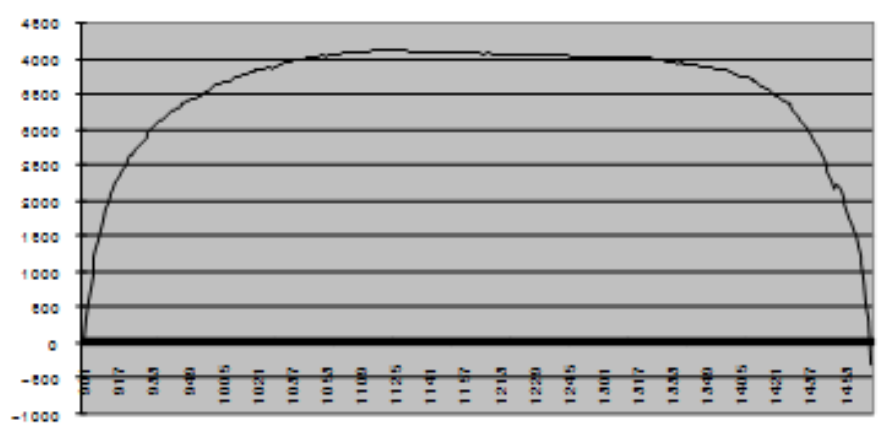

Figure 4. OID (5-year)

The times of accrossing above 4000 are the same. They are 10:40. The times of accrossing down below 4000 are 13:33 and 13:28 respectively. It means that nowadays investors tend to follow the market faster. The times of maximum open interest are the same which is 11:22 and the maximum contracts are 4138.55 both. This means the power of super investors who lead the market is not changed. But the investors who participate the market acclimate themselves to the market.

Table 1. Comparison between two OID curves

\begin{tabular}{|c|c|c|}
\hline Average duration & 2-year & 5-year \\
\hline last date & $10-05-31$ & $12-04-13$ \\
\hline Time Above 4000 & $10: 40$ & $10: 40$ \\
\hline Time Under 4000 & $13: 33$ & $13: 28$ \\
\hline Time Maximum & $11: 22$ & $11: 22$ \\
\hline Max Contracts & 4138.55 & 4138.55 \\
\hline
\end{tabular}

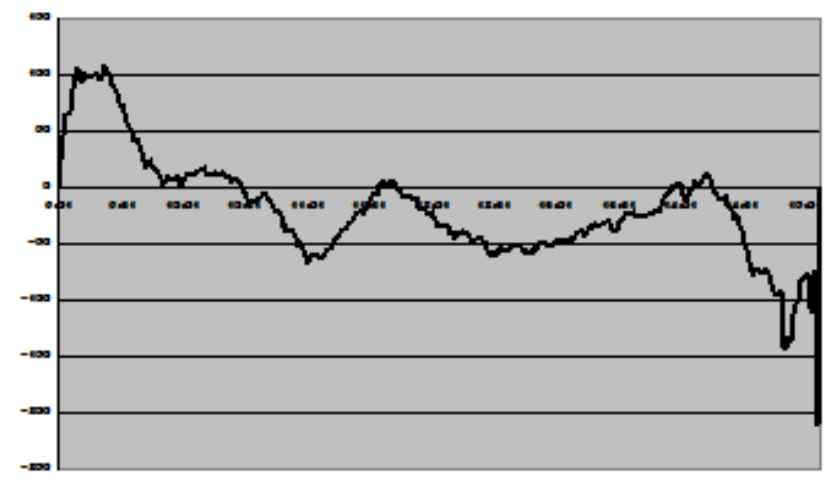

Figure 5. Difference between two open interest curves

The chart above shows the difference between two-year average graph and five-year average graph. In other words, this graph shows the recent trend of investors. From 9:00 to 10:00 the difference is rising up to 100 . This means that the super investors who lead the market try to handle faster. And when about 11:00 and 13:00, the difference decrease down to 50. This means the weak investors tend to acclimate themselves to the market. After 14:30 the difference fall to 200. This means investors come to waive nearly the closing time. 


\section{VOLATILITY STRATEGY}

Volatility strategy is based on the hypothsis that OID is relate to volatility. This strategy was suggested by $\mathrm{Ko}^{[1]}$ in 2010.

If the OID is increasing before the noon, the volatility of option market is also increased. And then if the OID is reducing after the noon, the volatility is also reduced.

With this properties, the two strategies are proposed. Buythensell strategy makes long straddle/strangle at 9:00 and liqudates it at 12:00. Sellthenbuy strategy makes short straddle/strangle at 12:00 and then also liquidates it near closing time, 14:40. For avoiding the volatility of near closing time, the time of liqudation of sellthenbuy stratedy is selected at 14:40.

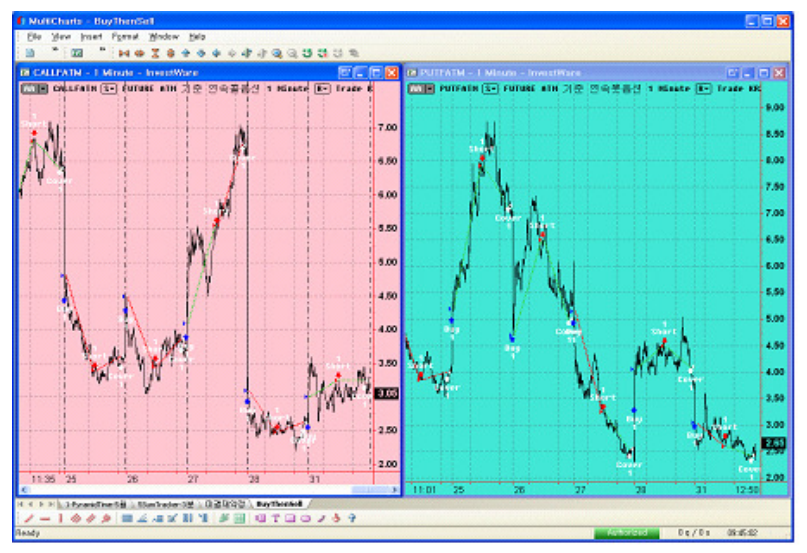

Figure 6. Strategy charts using Signals

To ensure the profitability of Buythensell, Sellthenbuy strategies, from 23 March 2009 to 31 May 2010 for 301-trading days are selected for an experiment.

These strategies are very simple. Buythensell strategy is buy both call and put option at 9:00 and liquidates both options at 12:00. Sellthenbuy strategy sell both call and put option at 12:00 and liquidates both options at 14:40. So after 15:00 there is no contract left and this features garantee avoiding the high overnight risk.

Table 2. Profits of volatility

\begin{tabular}{|c|c|c|c|}
\hline \multirow{2}{*}{} & \multicolumn{3}{|c|}{ Volatility strategy } \\
\cline { 2 - 4 } & total & BuythenSell & SellthenBuy \\
\hline ATM & $1.07 \%$ & $0.51 \%$ & $0.56 \%$ \\
\hline OTM 2.5 & $0.94 \%$ & $0.41 \%$ & $0.53 \%$ \\
\hline OTM 5 & $0.68 \%$ & $0.21 \%$ & $0.47 \%$ \\
\hline OTM 7.5 & $0.53 \%$ & $0.15 \%$ & $0.38 \%$ \\
\hline OTM 10 & $0.44 \%$ & $0.14 \%$ & $0.30 \%$ \\
\hline
\end{tabular}

As for the result of exercise price in above table, the ATM has the biggest profit. This means that the option at the money which is near the index is most influenced by super investors. In Korea, most of the trading in ATM is by foreigners which are regarded as super investors. 


\section{VELOCITY STRATEGY}

Volatility strategy is due to the hypothesis that the OID is related to the volatility. But if you review the real data, you would know the fact that the call and put options show some different characteristics. So this paper is worked up more in detail about this.

It is clear that the OID influence the volatility of options. But something that is more influenced by OID may exist.

Another hypothesis is that the OID influence the velocity of index. If the OID increase, the super investors try to move index into a certain level. And weak investors resist this pressure. And if the OID decrease, the leading investors win this try or find compromise index. And then the weak investors waive and adapt themselves to market.

The move of index has two direction. Because of the characteristics of stock, rising of index is slower but falling of index is faster relatively.

This characteristics make call option stagnate because of slow rising of index. But this makes put option rise rapidly.

As for the average data of long days enough, call options tend to decrease and put opionts tend to increase when the OID increase. This characteristics can be confirmed by simulation of real data.

When the OID decrease, put option which has risen more than its value finds the appropriate price. And call option which has been compressed is easy to increase slightly.

By considering this characteristics, this paper suggest velocity strategy which consists of Morning strategy and Afternoon strategy.

Morning strategy is that buying put option and selling call option at 9:00. And they are liquidated by $12: 00$.

Afternoon strategy is that selling put option and buying call ooption at 12:00. And they are liquidated by $14: 40$.

Table 3. Profits of velocity strategies

\begin{tabular}{|c|c|c|c|}
\hline \multirow{2}{*}{} & \multicolumn{3}{|c|}{ Velocity strategy } \\
\cline { 2 - 4 } & total profit & Morning strategy & Afternoon strategy \\
\hline ATM & $2.64 \%$ & $1.11 \%$ & $1.53 \%$ \\
\hline OTM 2.5 & $1.95 \%$ & $0.73 \%$ & $1.22 \%$ \\
\hline OTM 5 & $1.26 \%$ & $0.41 \%$ & $0.85 \%$ \\
\hline OTM 7.5 & $1.08 \%$ & $0.35 \%$ & $0.73 \%$ \\
\hline OTM 10 & $0.64 \%$ & $0.18 \%$ & $0.46 \%$ \\
\hline
\end{tabular}

Table 3 shows the result of simulation of velocity strategy. In ATM, the profit is $2.64 \%$ per a day. This amount is incredibly big because cumulative profit is enormous. 


\section{EXPERIMENTS AND RESULTS}

$\mathrm{Ko}^{[1]}$ brought the results of his simulation from 23 March 2009 to 31 May 2010 . This duration is a little over one year and 301 trading days. Symbols for experiments are based on the ATM, OTM of 2.5 points, OTM of 5 points, OTM of 7.5 points, OTM of 10 points.

In this paper the simulation duration is expended. From 23 March 2009 to 13 April 2012 is selected for the experiment. This duration is 769 trading days.

The straddle/strangle trade consists of both call and put options. But this paper simulates individual option separately. So when straddle get profit, the result shows which part of call and put options brings the profit.

Table 4. Simulation result of Call and Put respectively

\begin{tabular}{|c|c|c|c|c|c|c|c|}
\hline & strategy & & type & trades & profit & $\begin{array}{c}\text { Rate } \\
\text { profitable }\end{array}$ & MDD \\
\hline \multirow{8}{*}{ ATM } & \multirow{4}{*}{ BuyThenSell } & \multirow{2}{*}{$09: 00-12: 00$} & Call & 769 & $-1,321,000$ & 42 & $-2,210,000$ \\
\hline & & & Put & 769 & $4,650,000$ & 47 & $-1,754,000$ \\
\hline & & \multirow{2}{*}{$12: 00-14: 40$} & Call & 769 & $1,662,000$ & 46.42 & $-1,261,000$ \\
\hline & & & Put & 769 & $-6,549,000$ & 37.45 & $-7,283,000$ \\
\hline & \multirow{4}{*}{ SellThenBuy } & \multirow{2}{*}{$09: 00-12: 00$} & Call & 769 & $1,321,000$ & 55.79 & $-1,816,000$ \\
\hline & & & Put & 769 & $-4,650,000$ & 51.11 & $-5,417,000$ \\
\hline & & \multirow{2}{*}{$12: 00-14: 40$} & Call & 769 & $-1,662,000$ & 50.2 & $-2,510,000$ \\
\hline & & & Put & 769 & $6,549,000$ & 60.08 & $-1,940,000$ \\
\hline \multirow{8}{*}{ OTM1 } & \multirow{4}{*}{ BuyThenSell } & \multirow{2}{*}{$09: 00-12: 00$} & Call & 769 & $-563,000$ & 39.14 & $-1,508,000$ \\
\hline & & & Put & 769 & $3,380,000$ & 45.38 & $-1,529,000$ \\
\hline & & \multirow{2}{*}{$12: 00-14: 40$} & Call & 769 & $1,107,000$ & 44.47 & $-863,000$ \\
\hline & & & Put & 769 & $-5,445,000$ & 36.28 & $-6,013,000$ \\
\hline & \multirow{4}{*}{ SellThenBuy } & \multirow{2}{*}{$09: 00-12: 00$} & Call & 769 & 563,000 & 58.91 & $-1,600,000$ \\
\hline & & & \begin{tabular}{|l|} 
Put \\
\end{tabular} & 769 & $-3,380,000$ & 52.28 & $-4,189,000$ \\
\hline & & \multirow{2}{*}{$12: 00-14: 40$} & Call & 769 & $-1,107,000$ & 51.89 & $-1,780,000$ \\
\hline & & & Put & 769 & $5,445,000$ & 60.47 & $-1,816,000$ \\
\hline \multirow{8}{*}{ OTM2 } & \multirow{4}{*}{ BuyThenSell } & \multirow{2}{*}{ 09:00-12:00 } & Call & 769 & $-84,000$ & 38.1 & $-1,078,000$ \\
\hline & & & Put & 769 & $2,129,000$ & 43.95 & $-1,325,000$ \\
\hline & & \multirow{2}{*}{$12: 00-14: 40$} & Call & 769 & 429,000 & 41.87 & $-757,000$ \\
\hline & & & Put & 769 & $-4,135,000$ & 34.07 & $-4,553,000$ \\
\hline & \multirow{4}{*}{ SellThenBuy } & \multirow{2}{*}{$09: 00-12: 00$} & Call & 769 & 84,000 & 59.04 & $-1,426,000$ \\
\hline & & & Put & 769 & $-2,129,000$ & 53.45 & $-3,062,000$ \\
\hline & & \multirow{2}{*}{$12: 00-14: 40$} & Call & 769 & $-429,000$ & 51.24 & $-1,124,000$ \\
\hline & & & Put & 769 & $4,135,000$ & 60.86 & $-1,575,000$ \\
\hline \multirow{8}{*}{ OTM3 } & \multirow{4}{*}{ BuyThenSell } & \multirow{2}{*}{ 09:00-12:00 } & Call & 769 & $-138,000$ & 36.54 & $-872,000$ \\
\hline & & & Put & 767 & $1,766,000$ & 41.98 & $-1,125,000$ \\
\hline & & \multirow{2}{*}{$12: 00-14: 40$} & Call & 769 & 508,000 & 39.4 & $-604,000$ \\
\hline & & & Put & 767 & $-3,399,000$ & 34.29 & $-3,693,000$ \\
\hline & \multirow{4}{*}{ SellThenBuy } & \multirow{2}{*}{ 09:00-12:00 } & Call & 769 & 138,000 & 57.35 & $-1,024,000$ \\
\hline & & & Put & 767 & $-1,766,000$ & 52.93 & $-2,508,000$ \\
\hline & & $12 \cdot 00-14 \cdot 40$ & Call & 769 & $-508,000$ & 51.11 & $-1,011,000$ \\
\hline & & $12: 00-14.40$ & Put & 767 & $3,399,000$ & 59.97 & $-1,328,000$ \\
\hline & & $09 \cdot 00-12 \cdot 00$ & Call & 768 & $-255,000$ & 33.85 & $-757,000$ \\
\hline OTM4 & BuyThenSell & & Put & 766 & 723,000 & 40.08 & $-911,000$ \\
\hline & & 12:00-14:40 & Call & 768 & 615,000 & 36.33 & $-500,000$ \\
\hline
\end{tabular}




\begin{tabular}{|l|l|r|r|r|r|r|r|}
\hline & & Put & 766 & $-1,837,000$ & 33.03 & $-2,118,000$ \\
\cline { 3 - 7 } & \multirow{3}{*}{ SellThenBuy } & \multirow{2}{*}{$09: 00-12: 00$} & Call & 768 & 255,000 & 53.91 & $-732,000$ \\
\cline { 3 - 7 } & & Put & 766 & $-723,000$ & 53.39 & $-1,412,000$ \\
\cline { 3 - 7 } & \multirow{2}{*}{$12: 00-14: 40$} & Call & 768 & $-615,000$ & 47.4 & $-970,000$ \\
\cline { 3 - 7 } & & Put & 766 & $1,837,000$ & 57.96 & $-1,215,000$ \\
\hline
\end{tabular}

The simulation result shows that put options tend to increase in the morning and decrease in the afternoon. In contrast, call options tent to decrease in the morning and increase in the afternoon.

Table 5. Profits of volatility strategies (old)

\begin{tabular}{|c|c|c|c|c|c|c|}
\hline \multirow{2}{*}{} & \multicolumn{3}{|c|}{ BuythenSell strategy } & \multicolumn{3}{c|}{ SellthenBuy strategy } \\
\cline { 2 - 7 } & total profit & $\begin{array}{c}\text { average daily } \\
\text { profit }\end{array}$ & $\begin{array}{c}\text { daily profit } \\
\text { rate }\end{array}$ & total profit & $\begin{array}{c}\text { average } \\
\text { daily profit }\end{array}$ & $\begin{array}{c}\text { daily profit } \\
\text { rate }\end{array}$ \\
\hline ATM & $1,071,000$ & 3,558 & $0.51 \%$ & $1,244,000$ & 4,133 & $0.56 \%$ \\
\hline OTM 2.5 & 63,000 & 2,867 & $0.41 \%$ & $1,167,000$ & 3,877 & $0.53 \%$ \\
\hline OTM 5 & 39,000 & 1,458 & $0.21 \%$ & $1,040,000$ & 3,455 & $0.47 \%$ \\
\hline OTM 7.5 & 21,000 & 1,066 & $0.15 \%$ & 827,000 & 2,748 & $0.38 \%$ \\
\hline OTM 10 & 87,000 & 953 & $0.14 \%$ & 650,000 & 2,159 & $0.30 \%$ \\
\hline
\end{tabular}

Table 6. Profits of volatility strategies (updated)

\begin{tabular}{|c|c|c|c|c|c|c|}
\hline & \multicolumn{3}{|c|}{ BuythenSell strategy } & \multicolumn{3}{c|}{ SellthenBuy strategy } \\
\cline { 2 - 7 } & total profit & $\begin{array}{c}\text { average } \\
\text { daily profit }\end{array}$ & $\begin{array}{c}\text { daily profit } \\
\text { rate }\end{array}$ & total profit & $\begin{array}{c}\text { average daily } \\
\text { profit }\end{array}$ & $\begin{array}{c}\text { daily profit } \\
\text { rate }\end{array}$ \\
\hline ATM & $3,329,000$ & 4,329 & $0.62 \%$ & $4,887,000$ & 6,355 & $0.91 \%$ \\
\hline OTM 2.5 & $2,817,000$ & 3,663 & $0.53 \%$ & $4,338,000$ & 5,641 & $0.81 \%$ \\
\hline OTM 5 & $2,045,000$ & 2,659 & $0.38 \%$ & $3,706,000$ & 4,819 & $0.69 \%$ \\
\hline OTM 7.5 & $1,628,000$ & 2,117 & $0.30 \%$ & $2,891,000$ & 3,759 & $0.54 \%$ \\
\hline OTM 10 & 468,000 & 608 & $0.09 \%$ & $1,222,000$ & 1,589 & $0.23 \%$ \\
\hline
\end{tabular}

Above two tables show a difference of their simulation duration. Table 2 shows the recent trend. The difference is clear. In recent days, ATM has more influence rather than other OTMs. So the profit of ATM becom bigger than other OTMs.

Table 7. Profits of velocity strategies

\begin{tabular}{|c|c|c|c|c|c|c|}
\hline & \multicolumn{3}{|c|}{ Morning strategy } & \multicolumn{3}{c|}{ Afternoon strategy } \\
\cline { 2 - 7 } & total profit & $\begin{array}{c}\text { average daily } \\
\text { profit }\end{array}$ & $\begin{array}{c}\text { daily profit } \\
\text { rate }\end{array}$ & total profit & $\begin{array}{c}\text { average daily } \\
\text { profit }\end{array}$ & $\begin{array}{c}\text { daily profit } \\
\text { rate }\end{array}$ \\
\hline ATM & $5,971,000$ & 7,765 & $1.11 \%$ & $8,211,000$ & 10,677 & $1.53 \%$ \\
\hline OTM 2.5 & $3,943,000$ & 5,127 & $0.73 \%$ & $6,552,000$ & 8,520 & $1.22 \%$ \\
\hline OTM 5 & $2,213,000$ & 2,877 & $0.41 \%$ & $4,564,000$ & 6,777 & $0.85 \%$ \\
\hline OTM 7.5 & $1,904,000$ & 2,476 & $0.35 \%$ & $3,907,000$ & 5,811 & $0.73 \%$ \\
\hline OTM 10 & 978,000 & 1,271 & $0.18 \%$ & $2,452,000$ & 3,430 & $0.46 \%$ \\
\hline
\end{tabular}


In velocity strategy, BuythenSell is changed to Morning strategy and SellthenBuy is changed to Afternoon strategy. The initial time and liquidated time are the same. But selling is changed to buying in only call option.

\section{CONCLUSION}

The derivative market is made for hedging of stock market. For the purpose, it has a big leverage. This fact gives the investors chances to get profit. However it also makes speculative investors become bankrupt.

The prediction of market is not possible. If it is possible, all the investors go to one side that the trade is not established.

But the only fact of derivative products is that every product has its own expiration date. All the symbols including future, various options have its own expiration date when the open interest contracts must be liquidated.

An average curve of open interest contracts difference from the start shows that it has a regular pattern. This pattern is the fact and truth.

Ko suggested his paper that this pattern relate to the volatility. And suggested strategy get profit about $1.07 \%$ a day. But this amount of profit is just same to commission of 8 trades a day. If you have luck to find commission about $0.1 \%$ a trade, You can get profit.

This paper suggest another strategy. The pattern relate to the velocity. Time concept is very important to options. Because the price of option consist of time value and intrinsic value. The moving of stock index is differenct as rising and fall. The fall of stock index is faster than rising. This characteristics give call and put options a little bit different moving. In long time average, this characteristic is clear and investors can get profit with this characteristics.

As a simulations in the 517 trading day, The result gives that the amount of profit ATM is $1.44 \%$ except commissions of $0.15 \%$ a day.

And further research, it is very interesting to find a selection method of day which apply this strategy. This selection method gives surely more profit over $1.44 \%$ a day.

\section{REFERENCES}

[1] Ko Young Hoon, Analysis of Straddle trading strategy for KOSPI200 Stock index, Pan-Pacific Journal of Business Research, Vol 1. No 2. 2010.

[2] Balsara, Nauzer, Money Management Strategies for Futures Traders, John Wkley \& Sons. NewYork, 1998, pp. 276.

[3] Ko Young Hoon, Kim Yoon Sang, "Study on the performance analysis of push-pull strategy by Multicharts' Portpolio", journal on IWIT, Dec. 2010, 317-324

[4] Ko Young Hoon, Kim Yoon Sang, "A design of automatic trading system by dynamic symbol using global variables”, journal on KSDIM, Sep. 2010, 211 219.

[5] Ko Young Hoon, Kim Yoon Sang, "The profit analysis of straddle sell by entry-time and delta at system trading", journal on KSDIM, May 2010, 151 157.

[6] Ko Young Hoon, "MultiCharts multi-entry strategy for a portfolio of signal conversion system design", Software Engineering Institute of Society, Vol. 22, No. 1, 2009, pp. 44 52.

[7] Kang Suchul, Kim HeeChul, Investra - System Trading Strategies, Bumhan Books, 2004.

[8] Lukac and Brorsen, "The Usefulness of Historical Data in Selecting Parameters for Technical Trading Systems", The Journal of Futures Markets, John Wiley \& Sons, 1993. pp. 55 59. 
[9] Kim Jungyoung, System trading by technical index, Truth Search, 2001.

[10] Balsara, Nauzer, Money Management Strategies for Futures Traders, John Wkley \& Sons. 1998

\section{AUTHOR}

Young Hoon Ko He obtained B.S., M.S., and Ph.D. degrees in Electronics Engineering from Yonsei University, Seoul, South Korea, in 1991, 1993, and1997, respectively. He was a member of the Invited professors of Chungbuk University from 1997 to 1999. Since March 1999, he has been a Professor at the department of Computer Engineering, Hyupsung University, Hwasung, South Korea.

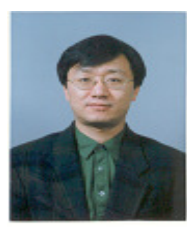

